\title{
MELANCOLIA A PINO, IMPASSE NO LOCUS TROPICAL: NOTAS SOBRE O POEMA “MARINHA", DE RUY ESPINHEIRA FILHO
}

\section{DEEP MELANCHOLY, TROPICAL LOCUS: NOTES ABOUT “MARINHA”, BY RUY ESPINHEIRA FILHO}

\author{
Cristiano Augusto da Silva JUTGLA ${ }^{19}$
}

\begin{abstract}
RESUMO: O presente trabalho, vinculado a pesquisa sobre poesia brasileira produzida durante a Ditadura Militar, procura analisar elementos estruturais do poema "Marinha", de Ruy Espinheira Filho, do livro Heléboro, de 1974. A leitura proposta se volta com especial ênfase à produtiva tensão constitutiva do poema, a qual provém do choque entre imagens paradisíacas e artefatos bélicos. Segundo a hipótese aqui levantada, tais instrumentos de guerra - perturbadores à paisagem tropical - estabelecem uma espécie de fantasmagoria do contexto repressivo em que o poema é escrito, fantasmagoria que, em meio a uma ensolarada praia soteropolitana, instaura um mal estar nas interpretações conciliadoras da marcadamente autoritária e violenta história brasileira.
\end{abstract}

PALAVRAS-CHAVE: Poesia brasileira contemporânea; Ruy Espinheira Filho; Melancolia; Violência.

ABSTRACT: The paper analyzes the poem "Navy" by Ruy Espinheira Filho. The analysis emphasizes the constitutive tension of the poem comes from the clash between images of paradise and instruments of warfare. According to our hypothesis, these instruments of war provide a kind of phantasmagoria of repressive context. This phantasmagoria on a sunny beach Salvadoran introduces a malaise in the interpretations of conciliatory authoritarianism and violent Brazilian history.

\footnotetext{
${ }^{19}$ Departamento de Letras e Artes (DLA) - Universidade Estadual de Santa Cruz (UESC) - CEP $45652-$ 090 - Ilhéus - BA - Brasil - E-mail: crisaug2005@ yahoo.com.br
} 
KEYWORDS: Brazilian contemporary poetry; Ruy Espinheira Filho; Melancholy; Violence.

\section{MARINHA}

Meus olhos testemunham a invisibilidade das ondinas, a lenta morte dos arrecifes e os canhões de Amaralina.

Vou, a passo gnominado, pisando a areia fina da praia.

Pombas sobrevoam os canhões de Amaralina.

Parece a vida estar completa na paz que o azul ensina. A brisa ilude a vigilância dos canhões de Amaralina.

Nem tua ausência, amor, perturba esta alegria matutina onde só há o claro e o suave... (E os canhões de Amaralina?).

Tudo está certo: mar, coqueiros, aquela nuvem pequenina... Mas - o que querem na paisagem os canhões de Amaralina?

(ESPINHEIRA FILHO, 1998, p.17).

\section{Introdução}

Quem se dedica ao estudo da poesia brasileira contemporânea, sobretudo a produzida durante os anos 70, encontrará em sua fortuna crítica uma interpretação segundo a qual as relações entre a lírica brasileira em diálogo com o contexto repressivo da Ditadura Militar desaguou em dois caminhos: ou à oclusão concretista e neoconcretista ou às inovações irônicas e corrosivas da poesia marginal. 
Assim, passadas quase quatro décadas do momento mais repressivo da Ditadura Militar (1964-1985), parece assentado na crítica que uma das marcas centrais da poesia produzida nos anos 70 é a reinvenção em chave irônica, por vezes sarcástica, do legado modernista. O grau de desmonte da tradição moderna chegara a tal ponto que o termo "marginal", cunhado por HOLANDA (1976, p.10), exemplifica, para o bem ou para o mal, o lugar discursivo avaliado pela crítica e que os próprios poetas acabaram por se colocar.

Nesse sentido, no lugar da razão cabralina ou do gauchismo drummondiano, os poetas da "geração mimeógrafo" optaram pelo desmonte, chegando muitas vezes à indiferença para com o que se entende por poesia mesmo entre os críticos mais acostumados com vanguardas ou revoluções estéticas.

A implosão feita pelos poetas de 70 da moderna tradição lírica brasileira não permaneceu mais do que uma década sem contrapontos críticos contundentes, dos quais o de DANTAS e SIMON parece ser o mais significativo:

Aquilo que tradicionalmente nada mais era do que as condições de produção de poesia no Brasil, freqüentemente autofinanciada ou cotizada, talvez pela peculiaridade artesanal e por ser um empreendimento de jovens, adquiriu de imediato a significação ambígua de uma 'resposta política às adversidades reinantes' interpretação esta que deu o tom. Cabe perguntar se a 'resposta política' se enunciava através de conteúdos e formas poéticas, se vislumbrava alguma experiência social nova, traduzida em outras relações e valores sócio-culturais ou se, simplesmente, o aspecto artesanal detinha algum teor politizante. A própria figura do poeta marginal ficou identificada à do vendedor que percorria bares, filas de cinema e teatro, promovia apresentações, recitais, happenings e até passeatas, para comercializar seu produto e abrir novos canais de veiculação. (DANTAS e SIMON, 1985, p.5-6).

Aliás, diga-se de passagem, a própria organizadora da famosa coletânea 26 poetas hoje advertia, quase dez anos antes da crítica de Dantas e Simon, o esgotamento de tal verve facilitadora da práxis poética: 
Entretanto, a aparente facilidade de se fazer poesia hoje pode levar a sérios equívocos. Parte significativa da chamada produção marginal já mostra aspectos de diluição e de modismo, onde a problematização séria do cotidiano ou a mescla de estilos perde sua força de elemento transformador e formativo, constituindo-se em mero registro subjetivo sem maior valor simbólico e, portanto, poético. (HOLLANDA, 1976, p.10).

A proposta deste artigo é mostrar que há um campo produtivo para pesquisa, quando o interessado se volta para o estudo da poesia brasileira escrita dos anos 70, cujos poemas que dialogam com o repressivo contexto de produção não passam necessariamente por uma resistência diretamente ligada, no que toca à fatura estrutural, com a exposição do momento histórico, beirando o panfleto, ou a oclusão neoconcretista.

Pois há poetas que buscaram estratégias estranhas a este binômio; um exemplo concreto é o poema "Marinha", de Ruy Espinheira Filho, que procuramos analisar neste trabalho. Semelhante a outros textos de seu primeiro livro ${ }^{20}$, intitulado Heléboro (1974), o poema "Marinha" caracteriza-se por uma estrofação predominantemente homogênea (4 quartetos, 1 quinteto). Junte-se a tal característica a predominância de versos de poucas sílabas, com um par de rimas em todas as estrofes; desse modo, "Marinha" é composto de uma estrutura tradicional de seu material lingüístico e poético.

${ }^{20}$ O primeiro livro publicado pelo autor foi Poemas (1973), em parceria com Antonio Brasileiro. Heléboro (1974) é o primeiro livro de autoria individual de Ruy Espinheira Filho, segundo informação do próprio autor (ESPINHEIRA FILHO apud MASSI, 1991, p.291). 
Com o ritmo controlado, o poema nos conduz cadenciadamente para seu final, quando se dá o ponto mais alto de tensão provinda de um jogo sutil e sereno entre duas forças.

Sutileza e serenidade notadas por Junqueira (1991), como marcas importantes nos dois primeiros livros de Espinheira Filho:

Trabalhando outra vez de preferência o metro curto, mais uma vez nos dá o poeta uma lição magistral de como conter e aguçar o seu discurso, cujo ritmo jamais se esgarça ou tropeça. Também sua linguagem (não raro metalinguagem) revela invulgar apuro formal, além de uma intermitente floração criadora. $\mathrm{O}$ autor desenvolve um estilo de extrema sobriedade e eficácia, o que não lhe expurga do verso nem o ludismo, nem a modulação cromática. (JUNQUEIRA, 1991, p.75).

As notas críticas propostas neste trabalho procuram dar especial ênfase ao jogo tenso entre natureza e história que perpassa todo o poema "Marinha". Segundo nossa hipótese, os canhões (perturbadores à paisagem tropical) criam no eu-lírico uma fantasmagoria do repressivo contexto de produção em que o poema se situa; ao mesmo tempo eles instauram um contraponto crítico às interpretações conciliadoras da violenta história brasileira justamente por meio de um símbolo ufanista: a natureza paradisíaca concretizada pela ensolarada praia de Amaralina. Semelhante releitura crítica dos espaços tradicionais da poesia brasileira aparece, por exemplo, no drummondiano “Nova canção do exílio", de A rosa do povo (1945):

\author{
Ainda um grito de vida e \\ voltar \\ para onde é tudo belo \\ e fantástico: \\ a palmeira, o sabiá, o longe. (DRUMMOND, 1991, p.69).
}


A atitude discreta e reflexiva do eu-lírico que evita entregar-se à sedutora natureza e aponta, por meio dos canhões, algo mal resolvido naquele ambiente aparentemente tão belo, lembra-nos uma ideia de Adorno sobre as relações da arte com a história, ideia esta bastante adequada à nossa análise:

Os estratos fundamentais que motivam a arte aparentam-se com o mundo objectivo, perante o qual retrocedem. Os antagonismos não resolvidos da realidade retornam às obras de arte como os problemas imanentes de sua forma. É isto, e não a trama dos momentos objectivos que defime a relação da arte à sociedade. (ADORNO, 1988, p.16).

As cinco estrofes do poema "Marinha" inicialmente causam, no leitor, um estranhamento pelo ritmo andante a contrastar com o desenrolar de seu conteúdo, que, pouco a pouco, caminha para um impasse. Ainda ligado a esse arreio ao discurso, outro ponto que chama a atenção é o fato de que embora a praia, tópico bastante desgastado na poesia brasileira, seja o espaço por excelência do poema "Marinha", o eu-lírico evita o emprego de hipérboles tão comuns a esse locus.

Esta recusa em inflar a enunciação força o leitor a rever, com semelhante calma também (sem apelos sentimentais ou neo-românticos, que tanto marcaram a poesia dos anos 70 no Brasil $^{21}$ ), a já tão decantada praia ensolarada, na qual a voz poética caminha a admirar o aparente quadro de perfeição que se apresenta a seus olhos.

As imagens gastas do locus tropical ("mar, coqueiros, / aquela nuvem pequenina...”) constituem, em uma primeira leitura, um ambiente tranquilo, rompido mais fortemente apenas pelas duas interrogações sobre os canhões de Amaralina nas duas estrofes finais.

Dessa maneira, a sensação inicial é a de que aqueles objetos são estranhos à paisagem, pois todo o conjunto lexical restante constitui um campo semântico pertencente à praia de Amaralina, situada na cidade de Salvador. Portanto, o discurso tende a qualificar a praia como um lugar aprazível, a ponto de criar, nas três primeiras estrofes, um efeito quase de suspensão da passagem do tempo devido à composição

\footnotetext{
${ }^{21}$ Ver, a esse respeito, a aguda discussão de Dantas e Simon acerca da poesia brasileira produzida nos anos 70 (1985).
} 
imagética daquele ambiente iluminado pelo sol a brilhar forte naquela manhã praticamente despida de nuvens. Assim, da primeira à terceira estrofe há uma predominância de uma natureza atraente, sedutora, que, por pouco, não provoca em seu admirador uma experiência de plenitude, como ele mesmo afirma na terceira estrofe: "Parece a vida estar completa / na paz que o azul ensina."

Desse modo, o intenso prazer provocado pela natura leva o eu-lírico a ironizar sutilmente a herança romântica na poesia brasileira moderna, quando revela que as sensações ali experimentadas são capazes de ensiná-lo a não sofrer nem mesmo pela falta da amada:

\author{
Nem tua ausência, amor, perturba \\ Esta alegria matutina \\ Onde só há o claro e o suave... \\ (E os canhões de Amaralina?) (ESPINHEIRA FILHO, 1998, p.17).
}

Há ainda outra ironia advinda da ambiguidade presente na palavra "falta", pois não sabemos se a amada ausente não está ali na praia por um acaso ou se ambos já não estão mais juntos no plano afetivo.

Porém, uma outra leitura indica que os versos do quadro idílico dividem espaço com os canhões da primeira à ultima estrofe, sempre situados após imagens paradisíacas; desse modo, toda estrofe começa pela sedução da natureza e termina pelo contraponto dos canhões que, militarmente, encerram cada uma das cinco estrofes. A justaposição de objetos artificiais aos objetos naturais em cada estrofe (ou seja, de um lado componentes da "alegria matutina"; de outro, instrumentos de guerra) desestabiliza e impede a plenitude do momento pelo eu-lírico.

Diante da presença dos canhões, tendemos a deixar de concentrar nossa atenção à leveza das imagens praieiras e solares; percebemos que, de fato, a vida não está completa, mas "parece estar completa". Sendo assim, não é à toa que este verso, também sutilmente composto de um verbo corriqueiro, aparece exatamente na metade 
do poema, isto é, na terceira estrofe, indicando a impossível comunhão com a natureza, pois entre a voz que nos "narra" aquela manhã e o quadro narrado há fragmentos da história no meio do caminho.

Desse modo, a sedução da praia começa a dividir espaço com a fantasmagoria provocada pelos canhões, que vão tomando vulto por meio de uma gradação crescente estrofe a estrofe. Vejamos.

Esta gradação ocorre por meio de um movimento sutil, mas constante, na importância dos canhões ao longo do poema. No plano estrutural, a força dos canhões aumenta pari passu à mudança de função sintática nas frases. As armas deixam de ser observadas e passam a sujeitos de sua vontade, ao mesmo tempo em que a natureza vai forçosamente tendo de ceder espaço e força a seus concorrentes.

Analisemos brevemente a gradação por meio da imagem dos canhões. Na primeira estrofe eles aparecem na frase como objeto direto do verbo "testemunhar".

\author{
Meus olhos testemunham [sujeito] \\ a invisibilidade das ondinas, \\ $[\ldots]$ \\ e os canhões de Amaralina. [objeto direto]
}

$\mathrm{Na}$ segunda estrofe, os canhões exercem a mesma função de complemento verbal, porém provocam certa precaução (ou seria medo, receio?) nas pombas, que são o sujeito da frase:

\author{
Vou, a passo gnominado, \\ pisando a areia fina \\ da praia. \\ Pombas sobrevoam [sujeito] \\ os canhões de Amaralina. [objeto direto]
}

Na terceira estrofe, na emblemática estrofe que assume a impossibilidade de comunhão com a natureza (posto que a vida parece, mas não está completa), a função de 
complemento verbal continua, porém há uma nova mudança no poder simbólico e fantasmagórico das armas a ponto de a própria natureza se valer de astúcias para fugir ao controle exercido pela "vigilância" dos canhões, que, embora complementos verbais, já se apresentam vivíssimos a ponto de exigirem da brisa o emprego de artimanha para que não seja por eles notada:

Parece a vida estar completa

na paz que o azul ensina.

\section{A brisa ilude [sujeito]}

\section{A vigilância dos canhões de Amaralina. [objeto direto]}

Frente ao incremento do poder dos canhões, as forças da natureza não conseguem apagar os traumas da história. No lugar da natureza desfrutável, a melancólica consciência do sujeito lírico ganha enorme peso sobre a história e seus impasses.

Estabelece-se, assim, um indissociável diálogo no poema: de um lado, a natureza, capaz de encantar, seduzir, provocar deleite por alguns momentos; porém, de outro lado, no entanto, continuam vivos os problemas históricos do autoritarismo brasileiro. Como dizia Drummond, sobre a permanência dos rastros traumáticos de sua história pessoal e coletiva, em seu epigramático e assustador "Cemitério de bolso": "Do lado esquerdo carrego meus mortos, / Por isso caminho um pouco de banda." (DRUMMOND, 1973, p.282).

$\mathrm{Na}$ quarta estrofe, definitivamente os canhões saem dos bastidores da cena e se tornam também protagonistas. No plano sintático, deixam de ser complemento verbal e passam à função de sujeito.

É curioso notar que nesta penúltima estrofe, a frase está travada pelos parênteses, o que não deixa margens para o preenchimento das posições anteriores ou anteriores do ponto de vista sintático: 
Nem tua ausência, amor, perturba

esta alegria matutina

onde só há o claro e o suave...

(E os canhões de Amaralina?) [sujeito]

Notemos que o efeito causado pelos parênteses é uma brusca pausa do discurso vinda logo após as reticências do efeito sinestésico do "claro e do suave". Suavidade esta rompida bruscamente pela parede formada pelo sinal gráfico do verso seguinte e da pergunta súbita, com seu início oralizado pela conjunção "e", que não liga o terceiro verso ao último, mas aos canhões da última estrofe. A fortíssima interrupção no ritmo sereno e controlado do poema instaura um corte definitivo nas pretensas totalizações ou idealizações que a praia e seus componentes idílicos poderiam promover sobre o eulírico.

$\mathrm{Na}$ última estrofe, o eu-lírico faz um apanhado, um resumo dos elementos naturais que lhe causam um efeito ducile, mas sempre incompleto, naquele cenário de “alegria matutina". De maneira explicitamente consciente, a voz poética joga com algumas das peças apresentadas ao longo das estrofes anteriores, reafirmando a beleza da praia: "Tudo está certo: mar, coqueiros, / aquela nuvem pequenina..." (ESPINHEIRA FILHO, 1998, p.17)

Porém, já é tarde: o jogo literalmente se inverteu, pois os canhões assumem funções sintáticas de sujeito, de comando, de ação, bem como passam a causar incertezas no eu-lírico e no leitor. Tanto assim que o poema, todo cadenciado, termina com uma conjunção adversativa seguida de um violento travessão que impõe outra pausa em seu ritmo, pausa esta mais brusca ainda do que os parênteses da estrofe anterior: "Mas - o que querem na paisagem / os canhões de Amaralina?" (ESPINHEIRA FILHO, 1998, p.17).

\section{Conclusão}


No poema "Marinha" instaura-se, ao final de sua leitura, uma forte tensão advinda da condição melancólica e reflexiva do eu-lírico, pois o contraste entre a beleza da praia, tradicional locus tropical de nossa literatura, e a incômoda presença dos canhões de Amaralina, indica que a voz poética resiste a apagar da memória os objetos traumáticos da história brasileira antes, durante e após 1964.

Em outras palavras, a presença dos canhões, sobretudo em um poema com uma bela praia como espaço discursivo, causa estranheza no leitor ao não seguir o estabelecido movimento de apagamento de rastros traumáticos, do silenciamento de impasses, como é o caso do autoritarismo que marca o contexto de produção do poema (em plena Ditadura Militar) e da cultura e própria formação da sociedade brasileira. Interessante notar também que "Marinha" permanece um texto que dialoga com seu tempo sem, no entanto, incorrer no discurso raso de fixação de marcas contextuais, evitando assim o datado panfleto. Pelo contrário, sua configuração é a sutileza.

A plena consciência da composição do quadro tropical, com a inextricável presença dos canhões de Amaralina, caminha para o impasse, pois não é possível fruir com monumentos de cultura (e de barbárie) no ambiente.

Outro ponto expressivo do poema aparece na perspectiva do eu-lírico frente à natureza e à história, uma vez que sua reflexão (composta de narração, descrição, com duas interrogações finais) não é maniqueísta ou restrita ao período de produção do poema, posto que os impasses históricos simbolizados nos vigilantes canhões de Amaralina não se iniciaram com o golpe de 64, não findaram com a abertura democrática, e permanecem em aberto.

Assim, o poema instaura a melancolia no lugar da fruição, do prazer físico advindo dos estímulos sonoros, táteis e visuais. $\mathrm{O}$ objeto de desejo não será alcançado ou superado, pois a história brasileira, simbolizada e concretizada pelo ferro dos canhões, que custa a se desgastar e desaparecer entre discursos totalizantes, não permite vitoriosos sem sujeitos melancólicos que vão à praia lembrar o que a maresia parece não conseguir apagar. 


\section{REFERÊNCIAS}

ADORNO, Th. Teoria Estética. Lisboa: Martins Fontes, 1988. p.12.

ANDRADE, C. D. de. Fazendeiro do ar. In: Poesia e prosa completa. Rio de Janeiro: Aguilar, 1973. p.282.

DANTAS, V.; SIMON, I. Poesia ruim, sociedade pior. Novos estudos CEBRAP, n.12, p.48-61, 1985.

ESPINHEIRA FILHO, R. Poesia reunida e inéditos. Rio de Janeiro: Record, 1998.

HOLLANDA, H. B. de. 26 poetas hoje. Rio de Janeiro: Labor, 1976.

JUNQUEIRA, I. O lirismo elegíaco de Ruy Espinheira Filho. In: O fio de

Dédalo: ensaios. Rio de Janeiro: Record, 1998. p.72-89.

MASSI, A. (Org.). Artes e ofícios da poesia. Porto Alegre: Artes \& ofícios; são Paulo: Secretaria Municipal de Cultura, 1991. p.291. 